\title{
Depression, Anxiety, Stress and Social Isolation in Hepatitis Patients
}

\author{
Pegah Ahmadi Sarbarzeh ${ }^{a}$, Saba Karimi ${ }^{\text {b }}$, Milad Jalilian ${ }^{a^{*}}$, Hadis Mosafer ${ }^{\text {a }}$ \\ ${ }^{a}$ Nursing Department, Nursing and Midwifery School, Student Research Committee, Kermanshah University of Medical Sciences, Kermanshah, Iran. \\ ${ }^{b}$ Nursing Department, Nursing and Midwifery School, Kermanshah University of Medical Sciences, Kermanshah, Iran.
}

Received 29 June 2020; Accepted 16 October 2020

\begin{abstract}
Hepatitis is a complex and chronic liver disorder. Due to the nature of the disease, these patients experience various levels of social isolation, anxiety, and depression. Therefore, this study was conducted to evaluate depression, anxiety, stress, and social isolation in patients with hepatitis B and C in Kermanshah. This study is descriptive-analytic research, the participants were the patients with hepatitis, who referred to liver disease center. Data collection was with Russell social isolation questionnaire and DASS-21 questionnaire. The questionnaires were completed by the patients. $67.3 \%$ of the patients were male. The mean age was $41.02 \pm 12.4$ years, and the majority of the participants were married (143; $67.8 \%$ ). The results showed that there is a direct and significant relationship between social isolation with depression, anxiety, and stress $(\mathrm{P}=0.001, \mathrm{P}=0.001, \mathrm{P}=0.001)$. In addition, results showed that there is a significant difference between the mean depression scores and age $(\mathrm{P}=0.048)$. Also, the results showed that there is a significant difference in the mean score of social isolation and education level $(\mathrm{P}=0.038)$. There is no significant difference between the other variables with depression, anxiety, stress, and social isolation $(\mathrm{P}>0.05)$. These results showed that there is a relationship between social isolation with anxiety, stress, and depression. Also, anxiety, stress, and depression in hepatitis patients are related to age and education level. So, it is suggested to provide effective programs in the care of these patients.
\end{abstract}

Keywords: Hepatitis; Depression; Anxiety; Stress; Social Isolation.

\section{Introduction}

Among the chronic diseases, hepatitis is one of the most important diseases in the world, that there are more than 350 million hepatitis patients in the world, which causes more than 500,000 deaths annually, especially in developing countries [1]. Hepatitis can be caused by infectious and non-infectious agents such as viruses, bacteria, fungi, parasites, alcohol, drugs, autoimmune diseases, and metabolic diseases [2]. Chronic hepatitis is a complex liver disorder with different causes and severity, and the inflammatory process and necrosis of the liver cells in hepatitis are lasted for at least 6 months [3]. During 2015-2018 in the US, the prevalence of hepatitis B virus (HBV) infection was 4.3\% [4] and was higher among men (5.3\%) than women (3.4\%). Also, the prevalence of hepatitis in EU/EEA country, reported between $0.0-7.5 \%$ and $0.0-27.6 \%$ for HBV and hepatitis $\mathrm{C}$ virus (HCV) respectively [5, 6]. So, an estimated 185 million people are infected with the $\mathrm{HCV}$ virus around the world and 3-4 million new infections are diagnosed annually [7]. This rate in hepatitis B patients estimated almost 400 million people all over the world [8]. Chronic hepatitis has often no symptoms, but it can be with several common symptoms such as fatigue, reduced ability in work, home, and school, loss of appetite, and mood changes [1,9]. Hepatitis B causes progressive liver damage; about $25 \%$ die prematurely from cirrhosis or hepatocellular carcinoma (HCC) [10]. Hepatitis disease can be a reason for depression, anxiety, and stress as well as a feeling of frustration and disappointment in patients [1, 11, 12]. Also, social

* Corresponding author: milad.jalilian@kums.ac.ir

$>$ This is an open access article under the CC-BY license (https://creativecommons.org/licenses/by/4.0/).

(C) Authors retain all copyrights. 
isolation and social stigma are other complications that occur in hepatitis patients [13, 14]. The prevalence of negative emotions in patients with chronic hepatitis has been reported between 1.51 to $38.1 \%$, that of these, $47 \%$ experience anxiety disorders and $68 \%$ a mild to moderate depression [8]. Depression, feeling emptiness and frivolity, feeling ineffective, and worthless in hepatitis patients have an effect on self-care activities [3].

In Kesen et al. study, the mean anxiety score was 7.56 and the depression score was 6.84 in hepatitis $\mathrm{C}$ patients [15]. The incidence of depression in chronic hepatitis $C$ patients was estimated at almost $25-44 \%$ [7, 16]. A study on 264 patients with chronic hepatitis $\mathrm{C}$, reported that $85.7 \%$ of them had no depression, $8.9 \%$ mild depression, and $4.5 \%$ moderate depression, and the anxiety in patients was $17.9 \%$ and $17 \%$ for mild to moderate anxiety and $0.9 \%$ for severe anxiety [17]. Depression in patients with hepatitis B can also affect the quality of life, diagnosis of disease and mortality rates [8].

Because the prevalence of psychological issues is high in hepatitis patients and due to their adverse consequences on the physiological and social status of patients, and wherever the lack of information in this issue, especially in Iran, the current study was conducted to evaluate depression, anxiety, stress, and social isolation in hepatitis B and C patients in Kermanshah.

\section{Materials and Method}

\subsection{Study Participants}

In this descriptive-analytical study, evaluated the level of depression, stress, anxiety and social isolation of patients with hepatitis B and C and their relation factors. The project was approved by the ethics committee affiliated with the Department of Research and Technology of Kermanshah University of Medical Sciences (Grant Number: 96231).

The participants were 211 patients with hepatitis B and C who referred to the hospitals of Kermanshah University of Medical Sciences, who had been diagnosed for at least 3 months. Patients with other chronic physical/psychological disease, patients who use of psychiatry medications, patients who did not willing to cooperate in the study after stating the research goals, and incomplete questionnaires were excluded. Patients were recruited as convenience sampling. The minimum number of patients according to the previous studies (Ataei et al. [17]) with a depression rate of 14.7\%, with $95 \%$ confidence level was estimated 185, so with considering an attrition rate of 12\% [18] Finally, 204 people were calculated and eventually we enrolled 211 patients.

\subsection{Data Collection}

The patients were assessed during the last eight months of 2019. The data were collected by a demographic check list and the 21-item questionnaire for depression, anxiety, and stress (DASS-21) as well as Russell social isolation questionnaire. The demographic checklist included 13 items that are reviewed by 12 faculty members of Kermanshah University of Medical Sciences as content validity and their comments were considered in the checklist.

DASS-21 is a standard and self-report tool developed by Antony et al. (1998) to measure the severity of a range of symptoms related to depression, anxiety and stress among individuals without a depression, anxiety, and stress diagnosis [19]. The DASS-21 questionnaire was used to assess the level of depression, anxiety, and stress. Content validity was sued to measure the validity of this scale [20, 21]. Covic et al. studied the internal consistency of the questionnaire using Cronbach's alpha, and reported the reliability index of 0.94 for depression and 0.87 for anxiety [20]. In other study, Cronbach's alpha was obtained for each individual and total scale was high (0.88), and the sensitivity of the questionnaire was $79.1 \%$ and its specialty was 77\% [18]. The Persian version of the questionnaire was studied in a Sahebi et al. study, with a Cronbach's alpha levels of 0.7, 0.67, and 0.49 for depression, anxiety, and stress dimensions, respectively [21].

DASS-21 has 21 items and three subscales of depression, anxiety, and stress. Each subscale includes 7 items. The lowest score for each question is zero and the highest score is 3 , in each dimension of depression, anxiety, and stress, the total score is between 0 - 4 (mild), 5 - 11 (moderate), and $\geq 12$ (severe).

For evaluating the social isolation, Russell questionnaire was used. this questionnaire was developed in 1980 by Russell et al. [22]. Reliability of the test was reported by Russell using test-retest (0.78) and Cronbach's alpha (0.96). Validity and reliability of the Persian version of the questionnaire were evaluated by Zarei et al. in 2016 [23]. The Cronbach's alpha was 0.91 . Russell questionnaire has 20 self-reported questions. The scoring of this questionnaire is conducted as Likert with options of never (1), rarely (2), sometimes (3) and often (4). The overall score of the questionnaire is between 20 and 80, and the higher score, indicating greater isolation and loneliness.

\subsection{Research Hypothesis}

It was hypothesized that evaluation of depression, anxiety, and stress and relation with social isolation and demographic characteristics in hepatitis patients. 


\subsection{Data Analysis}

Data were analysed by the Statistical Package for Social Sciences (SPSS v.18.0; SPSS Inc., Chicago, IL, USA) using descriptive statistics (mean and standard deviation) and inferential statistics (Kolmogrov-Smirnov, Spearman correlation test, and Mann-Whitney). In terms of education, the participants were subdivided into three categories: under diploma, diploma, and college education. In terms of economic status, the participants were classified into one of the poor and middle income $(\leq \$ 1400)$, and good income $(>\$ 1400)$ classes, based on their monthly income. In terms of age, the patients were subdivided in two categories: under 40 years and above 40 years. To analyse the data, the distribution of depression, anxiety, and stress variables was analysed by the Kolmogorov-Smirnov test, which showed they were abnormally distributed. Then, the Spearman correlation test was run to assess the relation between depression, anxiety, and stress variables and independent variables. The Spearman correlation test used to assess relation between social isolation and depression, anxiety, and stress. The Mann Whitney was applied to analyse the concurrent relationship between demographic variables and depression, anxiety, and stress. The level of significance was set at $\mathrm{p}<0.05$.

\section{Results}

In this study, 211 patients with hepatitis $\mathrm{B}$ and $\mathrm{C}$ were evaluated (Table 1). The mean and standard deviation (SD) of age was $41.02 \pm 12.40$ years. $67.3 \%$ of patients were male, 67.8 were married, $65.4 \%$ had under diploma education, $68.7 \%$ had a job, and $69.7 \%$ lived in urban areas (Table 1). $97.6 \%$ of patients had a poor to middle income and $58.8 \%$ had a history of smoking. Most of the patients (70.6\%), were diagnosed as hepatitis B and only $14.2 \%$ had a family history of hepatitis (Table 1).

The Mean \pm SD duration of disease was $1.90 \pm 1.13$ years which ranged from 3 months to 6 years. Mean and SD duration of disease was $1.86 \pm 1.10$ years ranged from 3 months to 6 years (Table 1).

Table 1. The frequency of demographic variables

\begin{tabular}{|c|c|c|}
\hline \multicolumn{2}{|c|}{ Variable } & \multirow{2}{*}{$\begin{array}{c}\mathbf{N}(\%) \\
142(67.3)\end{array}$} \\
\hline$C$ & Male & \\
\hline Gender & Female & 69 (32.7) \\
\hline \multirow{2}{*}{ Age } & $<40$ & $115(54.5)$ \\
\hline & $\geq 40$ & $96(45.5)$ \\
\hline \multirow{2}{*}{ Marital status } & Single & $68(32.2)$ \\
\hline & Married & $143(67.8)$ \\
\hline \multirow{3}{*}{ Education } & Under diploma & $138(65.4)$ \\
\hline & Diploma & $65(30.8)$ \\
\hline & College & $8(3.8)$ \\
\hline \multirow{2}{*}{ Job } & Unemployed & $66(31.3)$ \\
\hline & Employed & 145 (68.7) \\
\hline \multirow{2}{*}{ Location } & Urban & $147(69.7)$ \\
\hline & Rural & $64(30.3)$ \\
\hline \multirow{2}{*}{ Income } & Poor and middle & 206 (97.6) \\
\hline & Good & $5(2.4)$ \\
\hline \multirow{2}{*}{ Smoking } & Yes & $124(58.8)$ \\
\hline & No & 87 (41.2) \\
\hline \multirow{2}{*}{ Hepatitis type } & Type B & 149 (70.6) \\
\hline & Type C & $62(29.4)$ \\
\hline \multirow{2}{*}{ Family history } & Yes & $30(14.2)$ \\
\hline & No & $181(85.8)$ \\
\hline
\end{tabular}

The mean \pm SD of DASS and Russell social isolation scale reported in Table 2 and also, Kolmogrov-Smirnov test showed that they are abnormal $(\mathrm{P}<0.05)$ except for stress $(\mathrm{P}=0.058)$ (Table 2$)$.

The Mean of depression, anxiety, and stress were 10.94 $\pm 3.93,10.96 \pm 3.45$, and $10.02 \pm 3.94$ respectively. And, the Mean of social isolation score was $51.41 \pm 7.92$ (Table 2). 
Table 2. Kolmogrov-Smirnov to distribution of depression, anxiety, and stress, and social isolation

\begin{tabular}{cccccc}
\hline & Mean \pm SD & Potential range & Calculated range & Test statistic & P-value $^{*}$ \\
\hline Total DASS & $31.93 \pm 9.91$ & $0-63$ & $5-56$ & 0.078 & 0.003 \\
Depression & $10.94 \pm 3.93$ & $0-21$ & $0-20$ & 0.077 & 0.004 \\
Anxiety & $10.96 \pm 3.45$ & $0-21$ & $2-19$ & 0.070 & 0.013 \\
Stress & $10.02 \pm 3.94$ & $0-21$ & $0-21$ & 0.061 & 0.058 \\
Total Russell & $51.41 \pm 7.92$ & $20-80$ & $21-67$ & 0.115 & 0.001 \\
\hline
\end{tabular}

${ }^{*}$ Normal distribution in P-value $>0.05$.

Results showed that $43.6 \%$ of patients had severe depression, $34.6 \%$ had severe anxiety and $43.6 \%$ had severe stress. Also, of patients 50.2, 56.9, and $52.1 \%$ of patients had moderate depression, anxiety, and stress, respectively (Table 3). Depression, anxiety, stress, and social isolation was higher in male than female. Similarly, patients with type B had higher levels than type C patients (Table 4).

Table 3. Frequency of depression, anxiety and stress

\begin{tabular}{ccccc}
\hline \multirow{2}{*}{ DASS } & & Depression & Anxiety & Stress \\
\cline { 2 - 5 } & & $\mathbf{N}(\boldsymbol{\%})$ & $\mathbf{N}(\boldsymbol{\%})$ & $\mathbf{N}(\boldsymbol{\%})$ \\
\hline Mild & $0-4$ & $13(6.2)$ & $18(8.5)$ & $9(4.3)$ \\
Middle & $5-11$ & $106(50.2)$ & $120(56.9)$ & $110(52.1)$ \\
Severe & $>12$ & $92(43.6)$ & $73(34.6)$ & $92(43.6)$ \\
\hline
\end{tabular}

Table 4. Comparison mean of depression, anxiety, stress, and social isolation in terms of demographic variables

\begin{tabular}{|c|c|c|c|c|c|c|}
\hline & & Depression & Anxiety & Stress & Total DASS & Social isolation \\
\hline & & mean \pm SD & mean \pm SD & $\operatorname{mean} \pm \mathrm{SD}$ & mean \pm SD & mean \pm SD \\
\hline \multirow{2}{*}{ Gender } & Male & $11.17 \pm 4.01$ & $10.05 \pm 4.12$ & $11.04 \pm 3.36$ & $32.27 \pm 10.26$ & $51.66 \pm 8.20$ \\
\hline & Female & $10.94 \pm 3.93$ & $10.02 \pm 3.94$ & $10.96 \pm 3.45$ & $31.93 \pm 9.91$ & $50.89 \pm 7.36$ \\
\hline \multicolumn{2}{|c|}{ P-value } & 0.282 & 0.694 & 0.650 & 0.538 & 0.226 \\
\hline \multirow{2}{*}{ Age } & $<40$ & $10.46 \pm 3.67$ & $9.69 \pm 3.83$ & $10.87 \pm 3.45$ & $31.03 \pm 9.33$ & $50.81 \pm 8.03$ \\
\hline & $\geq 40$ & $11.52 \pm 4.17$ & $10.42 \pm 4.06$ & $11.07 \pm 3.45$ & $33.02 \pm 10.51$ & $52.13 \pm 7.78$ \\
\hline \multicolumn{2}{|c|}{ P-value } & $0.048^{*}$ & 0.684 & 0.201 & 0.173 & 0.133 \\
\hline \multirow{2}{*}{ Marital status } & Single & $10.75 \pm 3.35$ & $10 \pm 3.71$ & $10.97 \pm 3.30$ & $31.72 \pm 8.61$ & $50.86 \pm 7.34$ \\
\hline & Married & $11.03 \pm 4.19$ & $10.02 \pm 3.94$ & $10.96 \pm 3.45$ & $31.93 \pm 9.91$ & $51.41 \pm 7.92$ \\
\hline \multicolumn{2}{|c|}{ P-value } & 0.532 & 0.991 & 0.991 & 0.693 & 0.545 \\
\hline \multirow{3}{*}{ Education } & Under diploma & $11.11 \pm 4.03$ & $10.14 \pm 3.92$ & $10.82 \pm 3.48$ & $32.08 \pm 10.20$ & $51.83 \pm 7.97$ \\
\hline & Diploma & $10.36 \pm 3.68$ & $9.66 \pm 4.01$ & $10.96 \pm 3.42$ & $31 \pm 9.31$ & $49.95 \pm 7.64$ \\
\hline & University & $10.94 \pm 3.93$ & $10.02 \pm 3.94$ & $10.96 \pm 3.45$ & $31.93 \pm 9.91$ & $51.41 \pm 7.92$ \\
\hline \multicolumn{2}{|c|}{ P-value } & 0.337 & 0.577 & 0.127 & 0.357 & $0.038^{*}$ \\
\hline \multirow{2}{*}{ Job } & Employed & $11.02 \pm 3.93$ & $10.15 \pm 3.93$ & $11.02 \pm 3.58$ & $32.19 \pm 9.94$ & $51.8 \pm 8.05$ \\
\hline & Unemployed & $10.77 \pm 3.97$ & $75.9 \pm 3.99$ & $10.84 \pm 3.16$ & $31.37 \pm 9.89$ & $50.56 \pm 7.63$ \\
\hline \multicolumn{2}{|c|}{ P-value } & 0.927 & 0.612 & 0.738 & 0.718 & 0.274 \\
\hline \multirow{2}{*}{ Location } & Urban & $10.66 \pm 3.87$ & $9.91 \pm 3.86$ & $10.95 \pm 3.41$ & $31.53 \pm 9.56$ & $51.27 \pm 7.80$ \\
\hline & Rural & $11.57 \pm 4.03$ & $10.29 \pm 4.13$ & $11 \pm 3.56$ & $32.87 \pm 10.69$ & $51.73 \pm 8.25$ \\
\hline \multicolumn{2}{|c|}{ P-value } & 0.069 & 0.598 & 0.927 & 0.351 & 0.801 \\
\hline \multirow{2}{*}{ Income } & Poor-middle & $10.93 \pm 3.95$ & $10.01 \pm 3.93$ & $10.90 \pm 3.46$ & $31.85 \pm 9.93$ & $51.35 \pm 7.90$ \\
\hline & Good & $11.20 \pm 3.83$ & $10.60 \pm 5.02$ & $13.40 \pm 2.07$ & $35.20 \pm 9.57$ & $54 \pm 9.19$ \\
\hline \multicolumn{2}{|c|}{ P-value } & 0.879 & 0.738 & 0.111 & 0.609 & 0.518 \\
\hline \multirow{2}{*}{ Smoking } & Yes & $11.15 \pm 3.97$ & $10.37 \pm 3.90$ & $11.32 \pm 3.38$ & $32.85 \pm 9.80$ & $52.18 \pm 7.52$ \\
\hline & No & $10.64 \pm 3.89$ & $9.52 \pm 3.97$ & $10.45 \pm 3.50$ & $30.63 \pm 9.98$ & $50.32 \pm 8.39$ \\
\hline \multicolumn{2}{|c|}{ P-value } & 0.217 & 0.218 & 0.074 & 0.119 & 0.183 \\
\hline \multirow{2}{*}{ Hepatitis type } & B & $11.07 \pm 3.84$ & $10.20 \pm 3.80$ & $11.14 \pm 3.34$ & $32.43 \pm 9.43$ & $51.93 \pm 7.93$ \\
\hline & $\mathrm{C}$ & $10.59 \pm 4.17$ & $9.59 \pm 4.25$ & $10.54 \pm 3.68$ & $30.74 \pm 10.97$ & $50.17 \pm 7.83$ \\
\hline \multicolumn{2}{|c|}{ P-value } & 0.341 & 0.474 & 0.257 & 0.350 & 0.069 \\
\hline \multirow{2}{*}{$\begin{array}{c}\text { Family history } \\
\text { of hepatitis }\end{array}$} & Yes & $10.73 \pm 3.95$ & $9.93 \pm 3.99$ & $11.33 \pm 3.74$ & $32 \pm 9.91$ & $50.06 \pm 8.46$ \\
\hline & No & $10.97 \pm 3.94$ & $10.04 \pm 3.94$ & $10.90 \pm 3.40$ & $31.92 \pm 9.94$ & $51.64 \pm 7.83$ \\
\hline \multicolumn{2}{|c|}{ P-value } & 0.714 & 0.751 & 0.531 & 0.929 & 0.280 \\
\hline
\end{tabular}

* Significant at the level of 0.05 
The Spearman correlation test between DASS components and social isolation showed that there was a direct and significant relationship between social isolation and depression $(\mathrm{P}=0.001)$, social isolation and anxiety scales $(\mathrm{P}=0.001)$ and social isolation scale and stress $(\mathrm{P}=0.001)$. Although the difference between DASS components are not clear, but results showed that depression was stronger factor for social isolation $\left(r^{2}=0.245\right)$ (Table 5).

Table 5. Correlation between depression, anxiety and stress with social isolation

\begin{tabular}{ccccccccc}
\hline & \multicolumn{2}{c}{ Depression } & \multicolumn{2}{c}{ Anxiety } & \multicolumn{2}{c}{ Stress } & \multicolumn{2}{c}{ Total Score } \\
\hline & $\mathbf{r}\left(\mathbf{r}^{2}\right)$ & P-value & $\mathbf{r}\left(\mathbf{r}^{2}\right)$ & P-value & $\mathbf{r}\left(\mathbf{r}^{2}\right)$ & P-value & $\mathbf{r}\left(\mathbf{r}^{2}\right)$ & P-value \\
\hline \multirow{2}{*}{ Social isolation scale } & 0.495 & \multirow{2}{*}{0.001} & 0.360 & \multirow{2}{*}{0.001} & 0.469 & 0.001 & 0.518 & 0.001 \\
& $(0.245)$ & & $(0.129)$ & & $(0.219)$ & & $(0.268)$ & \\
\hline
\end{tabular}

As shown in Table 4, the results of the Mann-Whitney test showed that there was a significant difference between the mean depression scores and their age. A comparison of means showed that the mean of depression is higher in patient over 40 years of age. Also, the results of this test showed that there was a significant difference in the mean of social isolation of patients based on their education. There was no significant difference between the other variables with depression, anxiety, stress, and social isolation.

\section{Discussion}

Hepatitis is global health-treat that speared in whole of the world and causes many complications in patients and deaths annually. Cost of hepatitis treatment in china is 37 598.6 Yuan per Quality Adjusted Life Year (QALY) and in USA is $\$ 6000-\$ 21000$ pre QALY [24, 25]. HBV is referred to as a "Silent Killer" because infected persons can live 20-40 years before developing liver complications [25]. Psychiatric disorders can be occur in chronic patients like hepatitis. Hepatitis patients experience different levels of depression, anxiety, and social isolation [26-30]. Social isolation is higher in chronic patients and can cause other psychiatric disorders [31, 32]. In this study, we aimed to evaluate depression, anxiety, and stress in hepatitis patients, and calculate their relation with social isolation and demographic variables. Results showed $67.3 \%$ of patients were male and the mean age of the patients were $41.02 \%$. Other studies reported that most of patients were men and mean age was between $42-57$ years $[8,16,33]$.

Higher prevalence of hepatitis in young patients need future program for these patients because they are active workers in society. Results showed the mean of depression, anxiety, and stress were 10.94, 10.96, and 10.02 respectively. In addition, mean of Depression, anxiety, stress, and social isolation was higher in male than female and in Type B hepatitis than Type C. This study sowed the direct relationship between social isolation with DASS components. And, stress was stronger factor for social isolation. In hepatitis patients, depression can be cause of treatment failure [34]. He et al., reported that stress induces a shift in the type-1/type- 2 cytokine balance towards a type-2 response, which implicated a role of psychological stress in the course of HBV related immune-pathogenesis [35]. And, stresses have a continuing impact on hepatitis B antibody status [36]. A study, reported that patients with hepatitis B developed moderate to severe psychiatric including $22.4 \%$ with depression, $18.8 \%$ with anxiety, and $10.3 \%$ with both [27]. Vu et al. reported that, 37.5\% of chronic hepatitis B patients, experienced depressive symptoms [37].

In other study diagnosis of depression was $29.8 \%$ in HCV, and $3.7 \%$ in HBV. In addition, in this study reported that the most consistent correlates of depression status in Chronic Liver Disease (CLD) patients are being female and excessive alcohol consumption [38]. In other study, the prevalence of depression in hepatitis $\mathrm{C}$ patients (35.9\%) was higher than in hepatitis B patients (19.8\%) [39]. Alian et al. study, reported the frequency of depression was 68\% in hepatitis $\mathrm{B}$ and $86 \%$ in hepatitis $\mathrm{C}$ patients, and the frequency of mild depression was $14 \%$, moderate depression was $57.3 \%$ and severe depression was $28.7 \%$ [40]. These results were not versus to our results. Because we calculate the mean of depression and anxiety and these studies calculated the prevalence of them. This means that the prevalence of depression is higher in hepatitis $\mathrm{C}$ patients than Hepatitis B, but the mean of depression score in hepatitis patients is higher than hepatitis $\mathrm{C}$. This suggests that patients with type B hepatitis need more care than HCV patients about depression severity. A review study, prevalence of depression in HCV patients was 18.2-57.2\% [28]. Stewart et al. shows prevalence rates of $41 \%$ for anxiety and $27 \%$ for depression in hepatitis C patients [41]. A study showed that prevalence of depression and anxiety was higher in hepatitis B patients than HBsAg-positive inactive carriers [42], that it can be due to the nature of disease. Psychiatric disorders can be caused by medications and/or nature of disease [27, 43], Medications such as interferon can be reason for psychiatric disorders [33]. The hepatitis $\mathrm{C}$ virus effect the brain tissue and brain metabolites and cause depression [44]. In our study, the mean of social isolation was 51.41. The mean of social isolation was higher in male than female and in hepatitis B than hepatitis C. in studies reported that social stigma is worse in first days after diagnosis [45]. Reducing the social isolation can be useful especially in young patients. Results show the relation between social isolation and DASS components. This need further studies to confirm and show an available score for prediction of social isolation based on DASS components. Higher depression in older patients and in low and high educated patients reported in this study, and needed further studies. Psychiatric 
status in chronic hepatitis B and chronic hepatitis $\mathrm{C}$ patients may be beneficial in disease management and treatment. In Najaf et al. study, stress level was negatively correlated with age and was significantly more in single patients, and the anxiety level was less in patients with higher level of education [46].

\subsection{Limitation}

The studied participants were hospitalized patients, and the nature of hospitalization creates social isolation and shows a higher level of social isolation. This issue should be considered in future studies.

\section{Conclusion}

Hepatitis has a clear effect on the mental status of patients, which can affect many aspects of their lives. The results reported that the mean of depression, anxiety, stress, and social isolation are higher in hepatitis B patients compared with hepatitis $\mathrm{C}$ patients that are a new result. Most of the patients were at young ages and co-incidence of both hepatitis and Psychiatric disorders can cause failure treatment and adverse complications. Social isolation has a relation to depression, anxiety, and stress. And also, the results showed that social isolation has a relation with age and education. The higher age and less level of education have a negative relation to social isolation.

\section{Availability of Data and Materials}

The identified datasets used during the current study are available from the corresponding author on reasonable request.

\section{Funding}

The study was funded by Kermanshah University of Medical Sciences with Grant Number: 96231.

\section{Acknowledgements}

This research project was approved in Kermanshah University of Medical Sciences with approval Number 97786. The financial budget of this project was provided by Kermanshah University of Medical Sciences. The authors wish to thank the Department of Research and Technology of the university to assistance in this study.

\section{Authors' Contributions}

MJ and PAS, SB, and HM contributed in designing the study. PAS, MJ, and SB collected the data, and analysed by MJ and HM. the final report and manuscript were written by PAS, MJ, SB, and HM. All the authors read and approved the final version for submission.

All authors contributed to drafting and revising the article, gave final approval of the version to be published, and agree to be accountable for all aspects of the work.

\section{Declaration of Competing Interest}

The authors declare that they have no known competing financial interests or personal relationships that could have appeared to influence the work reported in this paper.

\section{Ethical Approval}

All procedures performed in studies involving human participants were in accordance with the ethics committee affiliated with the Department of Research and Technology of Kermanshah University of Medical Sciences (Approval Number 97786) and with the 1964 Helsinki declaration and its later amendments or comparable ethical standards.

\section{References}

[1] Keramat, F., Mamani, M., Torabian, S., \& Aliparast Dostkohi, M. (2013). Assessment and Comparison of Health-Related Quality of Life in Chronic Hepatitis B and C Patients with Healthy Persons in Hamadan Province. Avicenna Journal of Clinical Medicine, 20(2), 151-159.

[2] Organization WH. Hepatitis; (2020). Available online: https://www.who.int/hepatitis/en/. (Accessed on 14 April 2020).

[3] Hasanpour, D. A. (2014). The Concept Of Self-Care In Patients Diagnosed With Chronic Hepatitis: A Rogers Evolutionary Approach. The Journal of Urmia Nursing and Midwifery Faculty, 12(6):477-90.

[4] Kruszon-Moran, D., Paulose-Ram, R., Martin, C. B., Barker, L. K., \& McQuillan, G. (2020). Prevalence and trends in hepatitis B virus infection in the United States, 2015-2018. NCHS Data Brief, no 361 Hyattsville, MD: National Center for Health Statistics 2020 . 
[5] Hofstraat, S. H. I., Falla, A. M., Duffell, E. F., Hahné, S. J. M., Amato-Gauci, A. J., Veldhuijzen, I. K., \& Tavoschi, L. (2017). Current prevalence of chronic hepatitis B and C virus infection in the general population, blood donors and pregnant women in the EU/EEA: a systematic review. Epidemiology and Infection, 145(14), 2873-2885. doi:10.1017/s0950268817001947.

[6] Falla, A. M., Hofstraat, S. H. I., Duffell, E., Hahné, S. J. M., Tavoschi, L., \& Veldhuijzen, I. K. (2018). Hepatitis B/C in the countries of the EU/EEA: a systematic review of the prevalence among at-risk groups. BMC Infectious Diseases, 18(1). doi:10.1186/s12879-018-2988-x.

[7] Tang, L. S. Y., Masur, J., Sims, Z., Nelson, A., Osinusi, A., Kohli, A., ... Kottilil, S. (2016). Safe and effective sofosbuvirbased therapy in patients with mental health disease on hepatitis C virus treatment. World Journal of Hepatology, 8(31), 1318. doi:10.4254/wjh.v8.i31.1318.

[8] Zhu, H.-P., Gu, Y.-R., Zhang, G.-L., Su, Y.-J., Wang, K., Zheng, Y.-B., \& Gao, Z.-L. (2016). Depression in patients with chronic hepatitis $\mathrm{B}$ and cirrhosis is closely associated with the severity of liver cirrhosis. Experimental and Therapeutic Medicine, 12(1), 405-409. doi:10.3892/etm.2016.3271.

[9] Wang, L.-J., Chen, S.-W., Chen, C.-K., Yen, C.-L., Chang, J.-J., Lee, T.-S., ... Chien, R.-N. (2016). Treatment-emergent depression and anxiety between peginterferon alpha-2a versus alpha- $2 \mathrm{~b}$ plus ribavirin for chronic hepatitis C. BMC Psychiatry, 16(1). doi:10.1186/s12888-016-1135-8.

[10] Mast, E. E., Margolis, H. S., Fiore, A. E., Brink, E. W., Goldstein, S. T., Wang, S. A., Moyer, L. A, Bell, B. P., \& Alter, M. J. (2005). A comprehensive immunization strategy to eliminate transmission of hepatitis B virus infection in the United States: recommendations of the Advisory Committee on Immunization Practices (ACIP) part 1: immunization of infants, children, and adolescents. MMWR Recommendations and reports: Morbidity and mortality weekly report Recommendations and reports, 54(Rr-16):1-31. doi:10.1037/e548682006-001.

[11] Hajarizadeh, B., Richmond, J., Ngo, N., Lucke, J., \& Wallace, J. (2016). Hepatitis B-Related Concerns and Anxieties Among People With Chronic Hepatitis B in Australia. Hepatitis Monthly, 16(6). doi:10.5812/hepatmon.35566.

[12] Härter, M., Reuter, K., Aschenbrenner, A., Schretzmann, B., Marschner, N., Hasenburg, A., \& Weis, J. (2001). Psychiatric disorders and associated factors in cancer: results of an interview study with patients in inpatient, rehabilitation and outpatient treatment. European Journal of Cancer, 37(11), 1385-1393. doi:10.1016/s0959-8049(01)00136-8.

[13] Zacks, S., Beavers, K., Theodore, D., Dougherty, K., Batey, B., Shumaker, J., ... Fried, M. W. (2006). Social Stigmatization and Hepatitis C Virus Infection. Journal of Clinical Gastroenterology, 40(3), 220-224. doi:10.1097/00004836-20060300000009.

[14] Blasiole, J. A., Shinkunas, L., LaBrecque, D. R., Arnold, R. M., \& Zickmund, S. L. (2006). Mental and physical symptoms associated with lower social support for patients with hepatitis C. World Journal of Gastroenterology, 12(29), 4665. doi:10.3748/wjg.v12.i29.4665.

[15] Kesen, O., Kani, H. T., Yanartas, O., Aykut, U. E., ... Gok, B. (2019). Evaluation of depression, anxiety and quality of life in hepatitis C patients who treated with direct acting antiviral agents. The Turkish Journal of Gastroenterology, 30(9), 801-806. doi:10.5152/tjg.2019.18679.

[16] Vabo, I. L. C., Ferreira, L. E. V. V. de C., \& Pace, F. H. L. (2016). Depressive Episode Incidence in Patients with Chronic Hepatitis C Treated with Pegylated Interferon and Ribavirin. Arquivos de Gastroenterologia, 53(1), 20-24. doi:10.1590/s000428032016000100005 .

[17] Ataei, B., Javadi, A. A., Salehi, M., Mortazavi, R., Kassaian, N., Babak, A., Nokhodian, Z., \& Ataei, M. (2012). Relative Frequency of Depression and Anxiety in Chronic Hepatitis C Patients. Journal of Isfahan Medical School, 29(165).

[18] Tran, T. D., Tran, T., \& Fisher, J. (2013). Validation of the depression anxiety stress scales (DASS) 21 as a screening instrument for depression and anxiety in a rural community-based cohort of northern Vietnamese women. BMC Psychiatry, 13(1). doi:10.1186/1471-244x-13-24.

[19] Antony, M. M., Bieling, P. J., Cox, B. J., Enns, M. W., \& Swinson, R. P. (1998). Psychometric properties of the 42 -item and 21-item versions of the Depression Anxiety Stress Scales in clinical groups and a community sample. Psychological Assessment, 10(2), 176-181. doi:10.1037/1040-3590.10.2.176.

[20] Covic, T., Cumming, S. R., Pallant, J. F., Manolios, N., Emery, P., Conaghan, P. G., \& Tennant, A. (2012). Depression and anxiety in patients with rheumatoid arthritis: prevalence rates based on a comparison of the Depression, Anxiety and Stress Scale (DASS) and the hospital, Anxiety and Depression Scale (HADS). BMC Psychiatry, 12(1). doi:10.1186/1471-244x-12-6.

[21] Sahebi, A., Asghari, M., \& Salari, R. (2005). Validation of Depression Anxiety and Stress Scale (DASS-1) for an Iranianpopulation. Journal of Develomental psychology, 1(4), 36-54.

[22] Russell, D., Peplau, L. A., \& Cutrona, C. E. (1980). The revised UCLA Loneliness Scale: Concurrent and discriminant validity evidence. Journal of Personality and Social Psychology, 39(3), 472-480. doi:10.1037/0022-3514.39.3.472. 
[23] Zarei, S., Memari, A. H., Moshayedi, P., \& Shayestehfar, M. (2015). Validity and reliability of the UCLA loneliness scale version 3 in Farsi. Educational Gerontology, 42(1), 49-57. doi:10.1080/03601277.2015.1065688.

[24] Zhang, S. X., Yang, P. C., Cai, Y. L., Lin Y., \& Zou, Y. H. (2017). Cost-effectiveness of community-based treatment of chronic hepatitis B in China. Zhonghua liuxingbingxue zazhi, 38(7):860-7. doi:10.3760/cma.j.issn.0254-6450.2017.07.004.

[25] Chahal, H. S., Peters, M. G., Harris, A. M., McCabe, D., Volberding, P., \& Kahn, J. G. (2018). Cost-effectiveness of Hepatitis B Virus Infection Screening and Treatment or Vaccination in 6 High-risk Populations in the United States. Open Forum Infectious Diseases, 6(1). doi:10.1093/ofid/ofy353.

[26] Liu, Y., Tang, K., Long, J., \& Zhao, C. (2016). The association between hepatitis B self-awareness and depression: Exploring the modifying effects of socio-economic factors. Journal of Viral Hepatitis, 24(4), 330-336. doi:10.1111/jvh.12647.

[27] Hu, C. G., Yuan, G. S., Huang, H. P., Liu, J. W., Zhou, Y. C., Ren, Y. Y., ... \& Zhou, Y. P. (2017). Depression and anxiety caused by pegylated interferon treatment in patients with chronic hepatitis B and the therapeutic effects of escitalopram and alprazolam. Journal of Southern Medical University, 37(9), 1201-1205.

[28] Adinolfi, L. E., Nevola, R., Rinaldi, L., Romano, C., \& Giordano, M. (2017). Chronic Hepatitis C Virus Infection and Depression. Clinics in Liver Disease, 21(3), 517-534. doi:10.1016/j.cld.2017.03.007.

[29] Simonetti, G., Gitto, S., Golfieri, L., Gamal, N., Loggi, E., Taruschio, G., ... Andreone, P. (2018). Quality of life of hepatitis B virus surface antigen-positive patients with suppressed viral replication. European Journal of Gastroenterology \& Hepatology, 30(1), 14-20. doi:10.1097/meg.0000000000000999.

[30] Febrero, B., Ramírez, P., Martínez-Alarcón, L., Abete, C., Galera, M., Ríos, A., ... Parrilla, P. (2018). Quality of Life and Group Psychological Intervention in Patients with Cirrhosis on Liver Transplant Waiting List. Transplantation Proceedings, 50(9), 2626-2629. doi:10.1016/j.transproceed.2018.04.013.

[31] Henkel, H., Schmitz, M., Berghofer, G., Lang, A., Kager, A., Steiner, E., ... \& Rudas, S. (2000). Social vulnerability, social isolation of chronic psychiatric patients. Wiener medizinische Wochenschrift (1946), 150(22), 449-453.

[32] Holley, U. A. (2007). Social Isolation: A Practical Guide for Nurses Assisting Clients with Chronic Illness. Rehabilitation Nursing, 32(2), 51-58. doi:10.1002/j.2048-7940.2007.tb00152.x.

[33] Kawase, K., Kondo, K., Saito, T., Shimasaki, A., Takahashi, A., Kamatani, Y., ... Iwata, N. (2016). Risk factors and clinical characteristics of the depressive state induced by pegylated interferon therapy in patients with hepatitis $\mathrm{C}$ virus infection: A prospective study. Psychiatry and Clinical Neurosciences, 70(11), 489-497. doi:10.1111/pcn.12424.

[34] Leutscher, P. D. C., Lagging, M., Buhl, M. R., Pedersen, C., Norkrans, G., ... Langeland, N. (2010). Evaluation of depression as a risk factor for treatment failure in chronic hepatitis C. Hepatology, 52(2), 430-435. doi:10.1002/hep.23699.

[35] He, Y., Gao, H., Li, X., \& Zhao, Y. (2014). Psychological Stress Exerts Effects on Pathogenesis of Hepatitis B via Type1/Type-2 Cytokines Shift toward Type-2 Cytokine Response. PLoS ONE, 9(8), e105530. doi:10.1371/journal.pone.0105530.

[36] Burns, V. E., Carroll, D., Ring, C., Harrison, L. K., \& Drayson, M. (2002). Stress, Coping, and Hepatitis B Antibody Status. Psychosomatic Medicine, 64(2), 287-293. doi:10.1097/00006842-200203000-00012.

[37] Vu, T., Le, T., Dang, A., Nguyen, L., Nguyen, B., Tran, B., ... Ho, R. (2019). Socioeconomic Vulnerability to Depressive Symptoms in Patients with Chronic Hepatitis B. International Journal of Environmental Research and Public Health, 16(2), 255. doi:10.3390/ijerph16020255.

[38] Weinstein, A. A., Kallman Price, J., Stepanova, M., Poms, L. W., Fang, Y., Moon, J., ... Younossi, Z. M. (2011). Depression in Patients with Nonalcoholic Fatty Liver Disease and Chronic Viral Hepatitis B and C. Psychosomatics, 52(2), $127-132$. doi:10.1016/j.psym.2010.12.019.

[39] Mirabdolhagh Hazaveh, M., Dormohammadi Toosi, T., Nasiri Toosi, M., Tavakoli, A., \& Shahbazi, F. (2015). Prevalence and severity of depression in chronic viral hepatitis in Iran. Gastroenterology Report, 3(3), 234-237. doi:10.1093/gastro/gou091.

[40] Alian, S., Masoudzadeh, A., Khoddad, T., Dadashian, A., \& Mohammadpour, R. A. (2013). Depression in hepatitis B and C, and its correlation with hepatitis drugs consumption (interfron/lamivodin/ribaverin). Iranian Journal of Psychiatry and Behavioral Sciences, 7(1), 24.

[41] Stewart, B., Mikocka-Walus, A., Morgan, J., Colman, A., Phelps, M., Harley, H., \& Andrews, J. (2012). Anxiety and depression in Australian chronic hepatitis C outpatients: prevalence and predictors. Australasian Psychiatry, 20(6), 496-500. doi: $10.1177 / 1039856212460597$.

[42] Aktuğ Demir, N., Celik, M., Kölgelier, Ş., Sümer, S., Demir, L. S., İnkaya, A. Ç., \& Aksöz, S. (2013). Comparison of the level of Depression and Anxiety in Inactive Hepatitis B Carriers and Chronic Hepatitis B Patients. Turkish Journal of Psychiatry, 24(4): 248-252. 
[43] Golub, E. T. (2004). Screening for Depressive Symptoms Among HCV-Infected Injection Drug Users: Examination of the Utility of the CES-D and the Beck Depression Inventory. Journal of Urban Health: Bulletin of the New York Academy of Medicine, 81(2), 278-290. doi:10.1093/jurban/jth114.

[44] Younossi, Z. M., Henry, L., Park, H., Adeyemi, A., \& Stepanova, M. (2015). Depression and Chronic Hepatitis C (CH-C): A Common and Costly Association. American Journal of Gastroenterology, 110, S874-S875. doi:10.14309/00000434201510001-02085.

[45] Valizadeh, L., Zamanzadeh, V., Bayani, M., \& Zabihi, A. (2017). The Social Stigma Experience in Patients With Hepatitis B Infection. Gastroenterology Nursing, 40(2), 143-150. doi:10.1097/sga.0000000000000223.

[46] Hanan Najem Najaf, Dheyaa J. Kadhim, Ahmed J. Alkofee, \& Dheyaa A. Al-Mashhadani. (2019). Depression, Anxiety and Stress Among a Sample of Chronic Hepatitis C Patients in AL-Najaf Province /Iraq. International Journal of Research in Pharmaceutical Sciences, 10(4), 3170-3177. doi:10.26452/ijrps.v10i4.1616. 